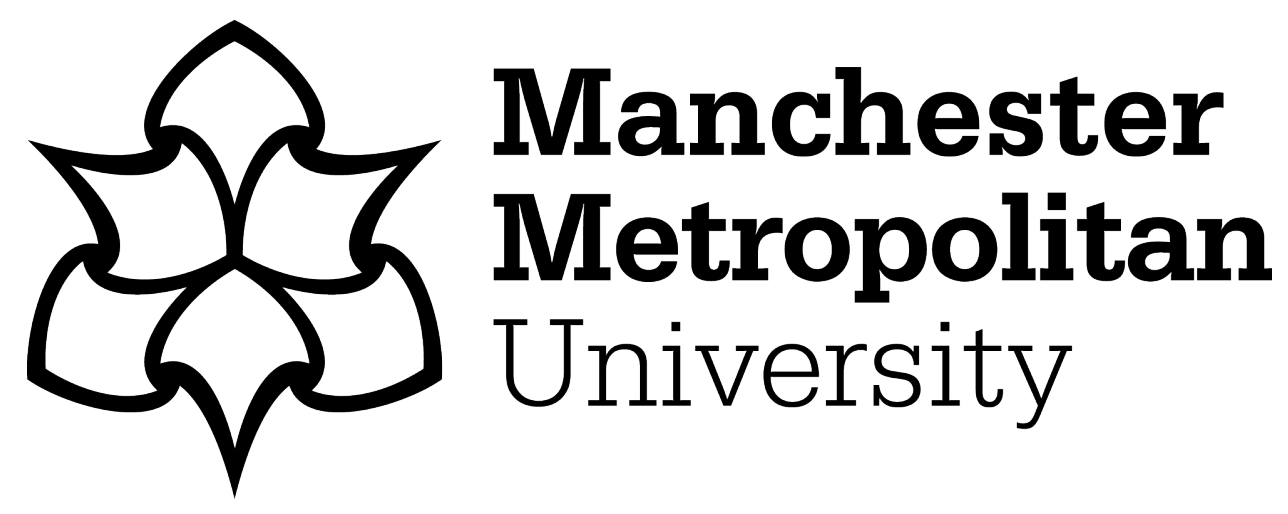

Edwards, P ORCID logoORCID: https://orcid.org/0000-0002-5814-4184 (2015) Where, how, who? Some questions for restorative justice. Safer Communities, 14 (3). pp. 139-146. ISSN 2042-8774

Downloaded from: https://e-space.mmu.ac.uk/67/

Version: Accepted Version

Publisher: Emerald

DOI: https://doi.org/10.1108/SC-05-2015-0014

Please cite the published version 


\section{Where, how, who? Some questions for restorative justice}

\section{Introduction}

The adoption of restorative justice in Britain has expanded greatly over the last decade, both in and outside the criminal justice system. Restorative justice has been seen as offering an unusual combination of benefits. It has appealed simultaneously to advocates of an enhanced role for victims in criminal justice, to believers in reducing reoffending by facilitating desistance, and to police forces committed to resolving problems of low-level disorder. It also, crucially, offers to deliver results in all these areas more quickly, less contentiously and (perhaps most important) at much less cost, in comparison to the conventional functioning of the criminal justice system. Since 2010 restorative justice has benefited further from the Coalition government's restrictions on public spending, which put police forces and other agencies in the position of needing to do more with less.

While this situation presents opportunities for ever-increasing numbers of people to benefit from restorative justice, it also prompts some questions, which will be set out in this paper. These are

- Where does restorative justice fit within the criminal justice system?

- How does restorative justice achieve its effects? and

- Who is the beneficiary of restorative justice - and how can the process be managed so as to benefit both victims and offenders?

This paper will argue that the answer to the third question - which also addresses the first two can be found by adopting a regulatory perspective, and in particular by foregrounding concepts of interdependency. The needs of victims and offenders, while they may both be met through restorative justice, are so different that a process designed to meet one may be oppressive and unjust to the other. The participatory equality on which just outcomes depend requires the articulation of relations of interdependency between participants. 


\section{Restorative justice: where?}

The first question to be asked is: where does restorative justice fit? At present in Britain, offenders and suspected offenders may be offered the option of restorative justice in several different settings. Restorative justice may take place

- without any criminal justice involvement (e.g. in schools)

- as a stand-alone procedure administered or facilitated by the police, without any criminal charge being brought

- accompanying a Young Person's Caution, following an admission of guilt

- as part, or all, of the conditions attached to a Conditional Caution, following an admission of guilt

- as a procedure undertaken after a guilty plea or finding of guilt but before sentencing, pending a deferred sentencing decision or in the time allowed for pre-sentence reporting

- as part, or all, of the conditions agreed with a young offender in a Referral Order, following a guilty plea or (at the discretion of the youth court) a finding of guilt

- as the reparative element of the conditions imposed on an adult offender in a Community Order, following a guilty plea or a finding of guilt

- as a stand-alone procedure offered to convicted offenders serving a sentence, without any necessary effect on the sentence

This is not an exhaustive list. While most - or all - of these forms of restorative justice may seem familiar and unexceptional, the range they cover is worth commenting on. An abstract model of criminal justice would look something like this: after a crime is committed, a suspect is charged and given the opportunity either to admit guilt or to plead not guilty and stand trial; following a guilty plea or a guilty verdict, the suspect is sanctioned (convicted) and subjected to a penalty. Viewed in this light, restorative justice is being offered

- when no crime has been committed

- after an admission of guilt, replacing a criminal sanction

- after a sanction, replacing part or all of a penalty

- as a penalty

- in addition to a penalty 
It is difficult to see how the same group of approaches to conflict resolution can convey such different messages in such different settings, ranging from informal and non-punitive resolution of non-criminal problems through to the formal punishment of crime. Punishment and restoration can be brought closer together if we assume that the rationale of punishment should not be the infliction of pain but communication - "an attempt to bring offenders to recognize the wrongs they have committed, and the need to make appropriate reparation for them" (Duff 2010: 302). Even on this basis, though, there is surely a crucial difference between the wrongs committed by an offender who has been found guilty in court and one who has broken no law. The underlying concern is that restorative justice may be adopted with multiple different goals in mind. Given the evident cost savings to be had from adopting restorative justice - suggesting that the diffusion of restorative justice will continue - this poses risks for the future of restorative justice, as practitioner expertise and organisational knowledge develop. On one hand, restorative justice may evolve into a variety of different practices with only the name in common; alternatively, it may end up serving some purposes well and others badly, with consequent costs to some groups who should ostensibly be benefiting from it.

Two main answers to this critique are available. It could be argued that even to think of restorative justice as an identifiable group of approaches would overstate the unity of the phenomena: perhaps the different forms of restorative justice are linked only by the kind of family resemblances that link together a game of Monopoly, a game of football and a game of poker (Wittgenstein 1953). However, the 'family resemblance' argument doesn't dispose of the problem so much as suggesting a way to resolve it, which would involve adopting new and different labels for different forms of restorative justice - something for which practitioners have shown no enthusiasm.

Alternatively and more ambitiously, it could be argued that viewing restorative justice in terms of criminal justice is the wrong starting point. In other words, perhaps the imperfect fit between restorative justice and existing criminal justice procedures merely reflects the idiosyncrasies of criminal justice, seen from the restorative standpoint; perhaps restorative goals and their achievement by restorative means are the primary reality, regardless of what relationship there is (if any) between the procedure and the criminal justice system. The argument for the primacy of restorative justice is persuasive to a point, but does not solve the problem so much as define it out of existence. Unless and until restorative justice supplants the criminal justice system altogether, the problem of the mismatch between the two paradigms will be practical as well as conceptual: if the same or similar restorative procedures are offered 
in punitive, non-punitive and non-criminal settings, the procedures will inevitably be inflected by the values associated with those settings, leading to confusion and distortion of the restorative goal. Of course, it could be argued that multiple different restorative goals are actually being sought in different contexts - so that 'restorative justice as penalty' would be a different process from 'restorative justice with no crime'. However, this would simply return us to the 'family resemblance' argument. The relationship between restorative justice and criminal justice appears uncertain and unresolved.

\section{Restorative justice: how?}

This relates to the second major question: how does restorative justice work? Given the emphatic opposition drawn between restorative justice and criminal justice in much of the literature, it should be possible to identify the features that make a restorative procedure restorative. Is there a particular set of interactions which always takes place when restorative justice is being undertaken? Braithwaite has written extensively $(1989,1999,2002)$ about 'reintegrative shaming', the process whereby representatives of a community bring an offender to the point of feeling shame for his/her past offences, before symbolically readmitting him or her to the community and removing any stigma of deviancy. Reintegration is contrasted with the 'degradation', stigmatisation and outcasting enacted by the court process (Braithwaite and Mugford 1994, Garfinkel 1956). Reintegrative shaming functions as an interaction in three stages: first, the victim, supported by the community, charges the offender with a shameful act and induces the offender to feel shame; second, the offender expresses shame; third, the community, with the victim's consent, assures the offender that he or she is accepted as a person, having taken responsibility for and condemned the shameful act. This model raises concerns (which Braithwaite acknowledges) about the capriciousness of actual communities, the potential for community judgments to be distorted by existing power relations and the operation of a tyranny of the (respectable) majority, and the possibility of offenders being subjected to burdensome and even stigmatising pressure in the cause of shaming.

In the contemporary British context these issues can be largely set aside, however, as the research evidence suggests two much larger problems with implementing 'reintegrative shaming'. First, readmittance to the community is not generally an observable outcome: "we only rarely saw reintegration into a 'community' ... This was not because restorative justice had 'failed' or was not reintegrative, but simply because a community in this sense did not exist" (Shapland et al 2006b: 521). Moreover, 'the community' tends not to be involved in 
restorative justice in any identifiable form: if anyone is involved other than the victim, the offender and a facilitator, it is almost invariably a relative or partner of the victim or offender. "What tended to be absent ... was any sense of the wider community, whether neighbours or people representing community organisations or groups. Hence supporters tended to have what we may call a 'star' relationship with the person whom they knew, with victims' and offenders' supporters generally being unknown to each other" (Shapland et al 2006a: 50) The presence of any kind of figure of informal authority within the community, to whom both the victim and offender could be expected to defer, is more or less unknown. This creates obvious difficulties for any kind of ceremony of readmittance to the community. (Both victim and offender could be expected to defer to the police, who are often involved in the role of facilitator; however, deriving informal 'community' authority from this source would be a double confusion of roles, between facilitator and participant and between moral and coercive authority.)

Secondly, the evidence suggests that the three-stage model of reintegrative shaming can rarely be observed, even when a meeting has been set up in such a way as to facilitate it. Expressions of disapproval for the offence and support for the offender have been observed, but with little or no correlation between the two (Shapland et al 2006a: 59); this suggests that the conferences did not proceed from disapproval of the offence to equally emphatic assurances that the offender was a good person rather than a stigmatised deviant - the crucial third stage of reintegrative shaming. It may be that this sort of public statement is 'un-British' in its effusiveness (Shapland et al 2006a: 54). Alternatively, the explanation may lie, again, in the absence of the network of horizontal social ties which would constitute a community; without this, the victim is unlikely either to know the offender well enough to form an opinion, or to be under any sort of social obligation to give the offender a good reference.

Another candidate for the key mechanism of restorative justice is the apology. Apologies, or encouragements to apologise, have a much stronger claim to universality. Restorative justice conference scripts typically cue the offender's apology fairly heavily. In less formal settings such as police-administered "street RJ", even the niceties of a prompt such as "Is there anything you'd like to say to the victim at this point?" may be dispensed with in favour of a blunt “Are you going to say 'Sorry'?”. Bottoms (2003) argues that a 'fully-accomplished apology' can change the relationship between victim and offender by reconfiguring their past and present identities. By apologising, in effect, the offender condemns his or her past self; by accepting the apology, the victim establishes a relationship with the offender in the present, 
replacing the previous (injured or vengeful) relationship with the offender's past self. The fully-accomplished apology is a small-scale and less ambitious version of reintegrative shaming. Rather than emerging from the encounter de-stigmatised and positively welcomed into a community, the offender ends up free from the threat of revenge, and in a neutral and non-threatening relationship with the victim (or no relationship at all).

The question then is, firstly, whether this simple mechanism is the motor that drives restorative justice: even in its most ambitious forms, is restorative justice fundamentally about creating a situation where an offender is willing to apologise and a victim to accept the apology? This is a loaded question, as there are certainly many examples of restorative justice which do fit this minimal template. If the answer is negative - if there is more going on, at least some of the time - we shall be committed either to disqualifying the more basic forms of restorative justice or to adopting the 'family resemblance' model, and conceding that restorative justice is not a single concept.

Secondly, approaching the same problem from another angle, we can ask whether a 'fully-accomplished apology' is achieved, or even realistically aimed for, across all the different procedures used to implement restorative justice and all the different settings in which it takes place. Can an apology be 'accomplished' if the victim is absent, and the police stand in for him or her? if the victim is collective or symbolic, as in some cases of vandalism and antisocial behaviour? if the victim is present but not the offender, and apologies are received in writing? This is separate from the question of whether, in practice, offenders volunteer an apology which is accepted, let alone whether the apology is accepted as sincere. Data from the conferences analysed by Shapland et al suggest that the vast majority of offenders do apologise $(90 \%)$ and that the majority of apologies (68\%) are felt to be sincerely given (Shapland et al 2007: 23-5). Intriguingly, $85 \%$ of victims in these conferences reported that they were either 'very satisfied' or 'quite satisfied' with the conference, despite the fact that $28 \%$ believed that the offender was not sincere ('No' or 'Not really'); a significant minority of victims seem to have been satisfied with the process, despite not believing that the apology they received was sincere (Shapland et al 2007: 27, 24).

\section{Restorative justice: who?}

At this stage, it seems reasonable to assume that restorative justice does stand for a single identifiable approach to conflict resolution - albeit one which may be pulled in different 
directions by its different points of implantation in the criminal justice system - and that its central procedural mechanism is an interaction between victim and offender which culminates in a 'fully accomplished apology'. (Depending how tightly an interaction is defined, this may put a question mark over some practices currently classed as 'restorative justice' - shuttle mediation and the written apology in particular. It is noticeable that these are not the forms of restorative justice which appear to be most popular or most effective.)

This prompts a third question: not how restorative justice works, but for whom. Advocates of restorative justice sometimes give the impression of dismissing this question with assurances that restorative justice is good for everyone (e.g. Braithwaite 1999): the victim is restored to the sense of self-worth, personal security and 'dominion' which he or she enjoyed before the crime; the offender is restored to a state free of stigma and unburdened by guilt or fear of revenge; and the community is restored to wholeness through the reknitting of social relationships, made possible both by the reacceptance of the offender and by the removal of the victim's burden of injury and/or vindictiveness.

As we have already seen, there is room for doubt as to whether the third mechanism operates, at least in the British experience of restorative justice. The notion of community should not be dismissed outright The existence of an active community is not a binary condition but the result of a combination of social interactions; the notion that initiating restorative practices in a 'fainting' community might be the 'vitaliser' that community needs is credible (Christie 1977: 12). In practice, as Bottoms notes, there has been little evidence of restorative justice playing this role in the years since Christie advanced this hopeful argument (Bottoms 2003: 82). Rather, restorative justice has developed in Britain in the absence of strong communities or informal moral authorities, and consequently has focused entirely on the restorative effects of the victim-offender interaction.

This leaves two possible beneficiaries: victims and offenders. The $85 \%$ satisfaction rate among victims noted above is matched by an $80 \%$ satisfaction rate among offenders (Shapland et al 2007: 27). Although this is encouraging, it is not conclusive; in particular, it does not tell us in what way the experience of restorative justice benefited the participants, and consequently cannot tell us whether it benefited them in the way that restorative justice theory would predict. To take an extreme example, the members of the notorious Australian sentencing group who "enthusiastically" sentenced a young offender to wear a sign identifying him as a thief appear 
to have found this exercise in stigmatisation satisfying (Braithwaite 1999: 97); this is not to say that it was any more restorative an experience for them than it was for the offender.

What, then, is the benefit which restorative justice offers - or should offer - to victims and offenders - and is the benefit the same for both sides? Certainly the two are both dealing with the consequences of the same offence; in this respect the metaphor of restoration is temptingly flexible, suggesting that the clock can simply be wound back to a time before the problematic event, freeing both parties of their respective burdens. However, since time cannot be rewound, the metaphor cannot be a useful guide to what actually needs to be done. Perhaps the furthest the commonality between victim and offender can be pushed is to say that both will benefit from ceasing to define themselves in terms of the offence, and that this change can - perhaps be brought about or hastened through restorative justice.

Framing it in these terms, however, highlights the differences between the two experiences. For the offender, the offence is an act that he or she undertook, either impulsively (violence, vandalism) or deliberately (violence, theft). In one case, the act was gratifying, an end in itself; in the other, it was a means to a desirable end (e.g. getting money). To move beyond the offence it will be necessary either for the offender either to cease taking gratification from mpulsive offending or to stop using criminal means to achieve his or her ends. Either of these patterns of offending behaviour will be supported by rationalisations and neutralisations; they may also be sedimented as a lifestyle and validated by the offender's social circle.

To disown even a first offence may involve substantial psychological adjustments and the abandonment of previously functional neutralisations (or, perhaps more realistically, their replacement with alternative neutralisations, permitting the offender to maintain his or her sense of a continuing identity while supporting law-compliant behaviour in the present). To abandon offending behaviour which is undertaken habitually and validated socially - and on which the offender may have become financially dependent - is necessarily a much larger undertaking: not so much a leap of faith as a trek.

For offenders, then, restorative justice is of value primarily insofar as it forms part of a movement of desistance, either awakening a desire to desist or - less spectacularly - validating the desire and helping the offender continue the development of a desisting sense of self. As Shapland et al write, "in order to agree sincerely to participate in restorative justice at all, offenders have to be at least on the cusp of trying to desist ... The conference itself, however, 
could provide an extra boost. Much of what was discussed in conferences was what could be called 'desistance talk"' (Shapland et al 2008: 42). How effective restorative justice actually is in this respect is still largely unproven, owing to a variety of practical and measurement-related issues. However, both the process of reintegrative shaming and the smaller-scale interaction of the 'fully-accomplished apology' are very much in line with the conceptualisation of desistance as driven by a sense of personal redemption and 'making good' (Maruna 2001).

For the victim, by contrast, the offence is a harm done, in three distinct but related senses. There is the actual harm, physical, material or financial - the setback to the victim's interests. Secondly, there is the harm done to the victim's autonomy and ability to organise his or her life - the qualities described by Braithwaite and Pettit as 'dominion', considered as a condition of 'resilient non-interference' (Braithwaite and Pettit 1990, Pettit and Braithwaite 1993). It is definitive of a crime, for the victim, that it is unexpected and potentially overpowering; to fear crime, on a continuing basis, is to live with an ever-present threat of an incursion that cannot be resisted, which is to say, to live without any sense of security. The fear of crime and the loss of security thus necessarily results in a drastically diminished sphere of effective freedom of action. Thirdly, there is the harm - even less tangible but equally real - done to the victim's dignity and sense of self by the experience of being the object of an illegal act. To be a victim of crime, in this sense, is to suffer the effects of something that should not have been allowed to happen. To put it another way, to be a citizen - a legal subject - is to have the right to security from harm; to be harmed is to have one's rights momentarily annulled, to cease to be a legal subject and become an object to be harmed or plundered.

Clearly, helping victims of crime to recover from this triple harm - material harm, harm to dominion, harm to subjecthood - is a very different proposition from an offender moving on from a pattern of voluntarily-undertaken behaviour, and it is not intuitively obvious that an interaction which assists one process will also assist the other. That said, an apology may have the merits of conveying respect for the victim as a person and the assurance that the victim is under no continuing threat; as such, it may be the message that the victim needs to hear in order to leave the effects of the offence behind, just as the acceptance of the apology is a message the offender needs to hear in order to begin to leave behind the habit of offending.

At this point in the argument, two opposite dangers loom. On one hand, there is a risk of instrumentalising victims. If restorative justice does consistently promote desistance, can we also expect it to serve the needs of victims? Does the association between restorative justice 
and desistance narratives risk placing victims 'in the service of offenders' (Ashworth 2000: 168)? This is unsatisfactory both to advocates of judicial due process and to enthusiasts for victims' rights, who argue that the victim's narrative should be at the centre of society's response to crime, rather than being relegated to the status of a witness statement.

On the other hand, if we take the role and the needs of victims as primary, there is the danger of instrumentalising offenders. The humanistic values of restorative justice should rein in any victims who take satisfaction from the stigmatisation - disintegrative shaming - of 'their' offender. The danger remains that the moral suasion exerted by the restorative interaction, prior to the apology being offered, may be experienced as stressful or humiliating, and that the apology may be offered as an expression of defeat, and in the hope of bringing the ordeal to an end. This is a particular concern in cases where the offending behaviour is well supported by habit and neutralisation, and where a lack of direct harm makes simple moral appeals unavailable. A graffiti artist, for example, may firmly believe that the offending behaviour is harmless, even positively valuable in its exhibition of skill and creativity; in a situation like this, efforts to induce shame may be oppressive, however supportive an apology would be for the victim's sense of autonomy and dignity.

\section{Conclusion: justice through regulation?}

The suggestion is, in other words, that the fully accomplished apology - with the processes of restorative justice which help to produce it - is an interaction which can meet the needs both of victims of crime wishing to overcome its effects and offenders who are ready to desist from crime. That said, the needs of the two groups are distinct, and it should not be assumed that both can be met by the same procedure; the possibility of a restorative justice procedure having restorative effects for one side but not the other must be kept in mind.

The question then is, finally, how this possibility can be averted. A clue may be offered by the regulatory framework within which Braithwaite situates restorative justice, and in particular the concept of interdependency. Braithwaite argues that restorative justice can function as a way for a community to regulate itself. The model is derived from business, where organisations can be effectively regulated using informal procedures which trade on a sense of shame while avoiding formal prosecution: thus Makkai and Braithwaite (1994) demonstrated a correlation between effectiveness in the regulation of old people's homes and the use of reintegrative shaming by the regulators. 
In the regulatory framework for the management of deviant behaviour, representatives of a community call troublesome individuals to account; the latter, once persuaded to feel ashamed of their actions, agree to behave in a more orderly way in the name of the shared values of the community. While the notion of community may be difficult to put into practice, as noted earlier, the concept of interdependency makes it more concrete. Braithwaite defines interdependencies as "attachments which invoke personal obligation to others within a community of concern" (Braithwaite 1989: 85); to the extent that people are connected by interdependencies, they will each have obligations to one another.

Significantly, as well as demonstrating the effectiveness of reintegrative shaming, Makkai and Braithwaite's 1994 study showed this approach to be particularly effective in a context of interdependency between regulator and regulated. We can suggest on this basis that regulation, and hence restorative justice, is at its best - and has the least potential to deliver unjust outcomes - when it is embarked on after the establishment or recognition of a genuine relationship of interdependency, and a common interest grounded in it. In the context of restorative justice, the more that victims and offenders recognise each other as being interdependent in some way, the more each will be motivated to meet the others' needs through the restorative process as well as using it to meet their own.

This is, perhaps, another way of approaching the question of equality of arms within the restorative process. Christie argues that when an offender faces a victim representative "with a limited amount of personal interest in the conflict", the outcome is a foregone conclusion: agreement between victim and offender degenerates into punishment. The situation would be different, he argues,

if the mediators on the boards were able to include the top management of the big firm or of the subway system or the municipality. In that case it would be possible to raise questions about how the shops are organised, if the temptations in the shop are exhibited in such a way that makes them close to irresistible to youngsters ... Or the question might be raised if the graffiti on the wall was not more beautiful and/or interesting than the huge advertisements for underwear?

(Christie 2004: 81-2). 
What is significant about these - perhaps utopian - examples is that they bring out the dependency of the victim on the offender (as customer, as future citizen) as well as the dependency of offender on victim. In the absence of any kind of articulation of interdependency - when the restorative process brings a shoplifter together with a security guard, or pits concerned citizens against suspected vandals - there can be no equality within the process; in these conditions just results are not likely to be achieved.

Restorative justice is a mechanism for collective self-regulation rather than for any kind of fact-finding or ascription of blame: this regulatory foundation may be the ultimate reason for the lack of fit between restorative justice and criminal justice (Braithwaite 2002). At the same time, it is defined by a commitment to delivering justice, and not merely restoration: a process which restored the status quo before a crime by cementing exploitative and unequal relations would be unsatisfactory, even if the participants were happy with it.

The aspirations of restorative justice advocates to give a voice to an active local community, as well as to individual victims and offenders, cannot work where such a community does not exist; the success of restorative justice in Britain to date has largely been achieved without any 'community' participation. Moreover, it cannot be assumed that restorative justice has an inherent tendency to promote communities; undertaken without the establishment of relationships of interdependency, it is liable to do little more than 'restore' participants to their place within existing inequalities and relations of power. That said, if the articulation of relationships of interdependency does promote the achievement of just results - and the restoration of both victims and offenders - then the promotion of the conditions for restorative justice may turn out to be the vitaliser for a revived active community.

\section{References}

Ashworth, A. (2000), “Victims' Rights, Defendants' Rights and Criminal Procedure”. In Crawford, A. and Goodey, J. (eds.) (2000), Integrating a Victim Perspective Within Criminal Justice: International Debates. Aldershot: Ashgate.

Bottoms, A. (2003), “Some sociological reflections on restorative justice”. In von Hirsch et al (2003), Restorative justice and criminal justice: Competing or reconcilable paradigms?. Oxford: Hart.

Braithwaite, J. (1989), Crime, shame and reintegration. Cambridge: Cambridge University Press. 
Braithwaite, J. and Mugford, S. (1994), "Conditions of successful reintegration ceremonies". British Journal of Criminology 34(2): 139-71.

Braithwaite, J. (1999), "Restorative justice: assessing optimistic and pessimistic accounts". Crime and Justice: A review of research 25:1-127.

Braithwaite, J. (2002), Restorative justice and responsive regulation. Oxford: Oxford University Press.

Christie, N. (1977), "Conflicts as property”. British Journal of Criminology 17(1):1-15.

Christie, N. (2004), A suitable amount of crime. London: Routledge.

Duff, R.A. (2010), “A criminal law for citizens”. Theoretical Criminology 14(3):293-309.

Garfinkel, H. (1956), “Conditions of successful degradation ceremonies”. American Journal of Sociology 61(5):420-24.

Makkai, T. and Braithwaite, J. (1994), "Reintegrative shaming and compliance with regulatory standards". Criminology 32(3):361-85.

Maruna, S. (2001). Making good: How ex-convicts reform and rebuild their lives.

Washington DC: American Psychological Association.

Shapland, J. et al (2004), Implementing restorative justice schemes (Crime Reduction Programme). Home Office Online Report 32/04.

Shapland, J. et al (2006a), Restorative justice in practice. University of Sheffield Centre for Criminological Research.

Shapland, J. et al (2006b), "Situating restorative justice within criminal justice". Theoretical Criminology 10(4):505-32.

Shapland, J. et al (2007), Restorative justice: the views of victims and offenders. Ministry of Justice Research Series 3/07.

Shapland, J. et al (2008), Does restorative justice affect reconviction?. Ministry of Justice Research Series 10/08.

Wittgenstein, L. (1953) (tr. G.E.M. Anscombe), Philosophical Investigations.

Oxford: Blackwell. 